\title{
Ativismo Virtual na Pós-Modernidade das Experiências e Afetos
}

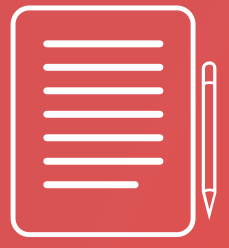

\author{
Virtual Activism in Post-Modernity of \\ Experiences and Affections
}

ARTIGO

Mariana Leite de Almeida

http://lattes.cnpq.br/1667986831327393

\section{Resumo}

Paradigmas dicotômicos ainda presentes na pós-modernidade nos permitem observar o quanto ainda estamos ligados à modernidade mais racionalista. Vivemos tempos coletivos, porém individualistas, vivemos ao mesmo tempo libertos e aprisionados, informados, mas constantemente passivos. Em diversos momentos vivemos, ainda, sem reconhecer o outro enquanto legítimo. Essa falta de reconhecimento do outro, muitas vezes, faz com que nos tornemos menos comprometidos socialmente e não demonstremos, no cotidiano social, a coletividade constantemente vivida na internet. As redes sociais nos mantêm fortemente ligados através de laços sensiveis, repletos de emoções e afetos. Essas relações colaboram na construção de uma ideia de que aprendizados se fazem possíveis graças ao que é experienciado com o mundo e, principalmente com o outro. Nesse contexto, o ativismo virtual se faz cada vez mais presente e necessário em nossas vidas, para podermos pensar criticamente sobre nossas experiências e sobre nossas vivências coletivas, buscando assim construir lugares melhores para se viver socialmente.

\section{Palavras-chave}

Ativismo Virtual. Pós-Modernidade.

Coletividade. Experiência. Afeto.

\section{Abstract}

Paradigms in opposition still present in postmodernity allow us to observe how much we are still connected to more rationalist modernity. We live collective but individualists times, we are at the same time freed and imprisoned, informed but often passives. Furthermore, we live without recognizing the neighbor as authentic. This fault make us less socially committed and we don't prove, in everyday social life, the community constantly lived on the internet. Social networks keep us strongly linked by sensitive ties, full of emotions and affections. These relationships collaborate to conceive the idea that learnings are made possible thanks to what is experienced with the world and especially with the neighbor. In this context, the virtual activism becomes increasingly present and necessary in our lives, so we can think critically about our collective experiences, thus seeking to build better places to live in society.

\section{Keywords}

Virtual activism. Post-Modernity.

Collectivity. Experience. Affection. 


\section{Introdução}

Vivemos na era do "quase livre" acesso à informação, na qual as dicotomias contemporâneas representam as experiências diárias e colaboram para a formação de seres cada vez mais sensíveis e decididos, e, por outro lado, constantemente informatizados, inseguros e duvidosos. Tal era nasce da ruptura da modernidade para a pós-modernidade que se caracteriza principalmente pela mudança na forma de pensar o mundo, passando de absolutamente racionalizada para uma maneira que promete equilibrar razão e emoção. Na modernidade predominou a exclusão e alguns valores, como a sensibilidade, foram considerados ultrapassados. Foi uma época na qual o conhecimento do corpo, o senso comum e os valores comunitários, em muitos momentos, foram deixados de lado. Ao contrário, a pós-modernidade, que teve seu início nas últimas duas décadas do século XX, apresenta aspectos muito mais voltados ao viver em comunidade, retomando algumas características dos tempos arcaicos (MAFFESOLI, 1995). Podemos notar que a coletividade acaba por definir os sujeitos no cotidiano tornando a época hoje vivida muito mais híbrida, hedonista e, ainda, preocupada com as experiências diárias banais apreendidas a partir do conhecimento sensível.

Dessa maneira, tendemos a acreditar que o mundo configurou-se de modo diferente no momento em que os princípios da modernidade foram considerados ideais já ultrapassados. Passamos a falar em pós-modernidade e construímos uma barreira monumental, blindada e imaginária entre as duas formas díspares de se pensar o mundo. 0 problema - que talvez nem mesmo se configure definitivamente enquanto algo negativo - foi que percebemos que os pontos de vista, formas de pensar e maneiras de agir de hoje eram, às vezes, muito distantes da modernidade e, em outras vezes, muito próximos. Descobrimos, assim, e para além dessa questão, a pluralidade da nossa época. Passamos a sentir seus efeitos e a questionar tais relações de similaridades e diferenciações.

Este questionamento se deu, e se dá, à medida que vamos percebendo o mundo a nossa volta e criando com ele significações para além da simples ação de deslocar-se pelo espaço, ou de cumprir tarefas automatizadas em determinado tempo. Tal questionamento surge no ato 
de (re)pensar não só o espaço no qual estamos inseridos e o tempo de duração de nossas ações como também, e essencialmente, de re(pensar) nossas vivências, motivações cotidianas e maneiras com as quais nos relacionamos com o outro. Tais indagações resultam na tentativa de compreender a época na qual estamos inseridos e quais os reflexos das nossas ações diante da sociedade que vivenciamos. Ou seja, buscam compreender a pós-modernidade através de nossas experiências estéticas - experimentando o mundo e o pensando ao mesmo tempo - e, a partir disso, apreender a estruturação plural e as diversas possibilidades existentes nesta época.

\section{Pós-modernidade e comunicação}

Os novos modelos de comunicação e de relacionamento que surgiram na pós-modernidade - advindos, geralmente, da revolução tecnológica aliada às diversas maneiras de se perceber o mundo nos dias atuais guiam-nos para um cotidiano repleto de trocas afetivas moldadas no vínculo comunitário e de interesses individuais naturais em uma sociedade edificada a partir do mercado de consumo. Logo, são comuns as maneiras divergentes de se caracterizar o tempo vivido. Maffesoli (1995) considera a época em que vivemos essencialmente coletiva, propícia às relações, à comunicação e à convivência, e à preocupação com o outro. Bauman (1999; 2001) pensa diferente; para ele a contemporaneidade assume como característica uma individualização muito agravante e, pior, fatídica: nem mesmo teríamos escolha, apenas seguimos o modelo de relação com a sociedade imposto pelo sistema.

As tribos, redes e grupos de afinidades e de interesse, unidos por paixões em comum, invadem nosso cotidiano. Para Maffesoli (1998), esta é uma das manifestações que melhor representam o que vivemos atualmente. Segundo ele, a tribalização do mundo é reflexo das nossas relações sociais cada vez mais coletivas; nos organizamos em grupo e desejamos fazer parte das coletividades, aspirações naturalmente respaldadas na afetividade e no estar-junto. Claro que ainda dedicamos tempo aos nossos valores íntimos e pessoais, mas estes são edificados para podermos nos entregar ao ideal comunitário. É nesta inserção coletiva que consiste a "transfiguração do político" própria da pós-modernidade, ou 
seja, o que resulta de "quando a ambiência emocional toma o lugar da argumentação ou quando o sentimento substitui a convicção" (MAFFESOLI, 2011, p.147). Nesta estruturação social que se dá principalmente através do sentimento, do afeto e da vontade de estarmos unidos, compreende-se porque o sujeito só existe enquanto inserido na coletividade (MAFFESOLI, 1997). O sujeito, sempre em relação com o outro e tentando ser aceito nos agrupamentos sociais, guia a sua existência com o foco no estar-junto. Suas ações, estilos, formas de pensar e de agir seguem o caminho que conduz à coletividade. Todavia, embora essas características traduzam as nossas ações enquanto seres humanos, ou seja, o desejo intrínseco à nossa espécie de viver em comunidade, elas não exprimem por completo a realidade vivida na pós-modernidade.

A época em que vivemos é, também, assinalada por aspectos que vão para além do ideal comunitário, e estes igualmente interferem na forma com que nos relacionamos com o mundo e com as pessoas a nossa volta. Para Bauman (2001), uma das principais particularidades do que denomina "modernidade líquida" é o mercado de consumo cada vez mais consolidado. Tal mercado - suas práticas e exigências de adaptação -, segundo o autor, é o que realmente guia nossas ações e escolhas, desde as mais banais até as ligadas às nossas identidades, por exemplo. É também esse mesmo mercado de consumo que torna a nossa sociedade tão individualizada. Vemo-nos presos às responsabilidades que nos são impostas, muitas vezes apresentadas como consequências de supostas liberdades, e acabamos por agir, incontáveis vezes, de forma individual. 0 consumo exacerbado e a posse de objetos de consumo que definem, hoje, nosso "grau" de felicidade, são reflexos do livre movimento de capital e da liberdade de mercado - principal preocupação da economia pós-moderna - que nos direcionam a uma existência individual por obrigação e não individual por conquista, um aspecto importante para vida coletiva. Para Bauman (2005), esse é o principal problema da individualização contemporânea: ela nos é imposta e não construída (como deveria ser por cada um de nós).

De ambas as maneiras, essencialmente coletiva ou individualizada de forma imposta, a sociedade pós-moderna (bem como suas relações sociais e interpretações de mundo) tem suas reflexões configuradas de dois 
modos. Ora respaldadas nas características comunitárias intrínsecas ao ser humano e nos agrupamentos sociais encontrados no cotidiano; ora na individualização (por vezes construída, por vezes imposta) das nossas ações e convivências com as pessoas, com o ambiente e com os objetos de consumo cotidianos. Coletividade e individualização vêm, assim, a desembocar em nossas vivências e experiências estéticas, frívolas ou não.

Hoje, as manifestações de coletividades e o aumento de possibilidades de relacionamento acontecem principalmente através da internet. É no meio virtual que nos comunicamos com frequência; que entramos em contato com diversas realidades e rotinas de vida; que nos informamos, descobrimos uma nova forma de ver e entender o espaço e ficamos conectados, de forma não física, ao mundo que nossos olhos não conseguem ver de perto e que alguns de nossos sentidos não podem perceber. $O$ virtual é potência. Estar no ambiente virtual é estar diante de inúmeras opções de ação que, muitas vezes, potencializam nossas vivências diárias. $\mathrm{O}$ virtual está cada dia mais atrelado ao cotidiano, e essa é uma característica essencialmente contemporânea.

É impossível falar de pós-modernidade sem falar nas novas formas de comunicação surgidas com a internet. Estamos seguidamente conectados, mais em relação com o mundo e as pessoas que dele fazem parte. A variedade de informações propagadas pela rede de computadores nos permite estar cientes de inúmeras realidades com as quais, porvezes, nem mesmo teríamos contato através do convívio físico. Além disso, a nossa rotina virtual define não só muitas de nossas ações como, também, muitas de nossas identidades. 0 mundo virtual é uma porta aberta para o entendimento de parte do nosso mundo, das nossas semelhanças e diferenças enquanto seres sociais. Mas será que esta crescente virtualização da sociedade prejudica a nossa visão de realidade?

Apesar da pré-concebida antagonia entre virtual e real, Pierre Lévy (1996) não acredita que ambos se contrariam. Para o filósofo da informação, a virtualização não se realiza apenas dentro de máquinas computacionais, mas, sim, em um processo de questionamento e problematização dos meios. Logo, o virtual existe, e se ele existe, é real. Para Lévy, o virtual, ao contrário do que costumamos pensar, se opõe diretamente ao atual. Virtualizar é o questionamento, atualizar é a resolução 
do problema em si. É a resposta aqui e agora. O virtual existe enquanto potência. $O$ atual acontece.

Já o virtual não se opõe ao real, mas sim ao atual. Contrariamente ao possível, estático e já constituído, o virtual é como o complexo problemático, o nó de tendências ou de forças que acompanha uma situação, um acontecimento, um objeto ou uma entidade qualquer, e que chama um processo de resolução: a atualização. Esse complexo problemático pertence à entidade considerada e constitui inclusive uma das dimensões maiores (LÉVY, 1996, p. 16).

Embora o virtual possa ser visto enquanto potência e possibilidade, para Bauman, a internet apresenta diversos reflexos negativos. Entre eles, o autor cita o fato de, hoje, os laços humanos se darem principalmente através da rede, ambiente no qual conectar e desconectar são ações muito fáceis. Essa relação permeada pelo computador, segundo o Bauman (2011), é muito diferente das relações que constituímos de forma pessoal. Em contrapartida, Maffesoli $(1998 ; 2012)$ acredita que na pós-modernidade, caracterizada pela sinergia entre o arcaico e desenvolvimento tecnológico, as tribos contemporâneas "florescem" devido, justamente, à expansão da internet e da tecnologia. Por vezes, realmente, dedicamos-nos tanto à internet e a seus utensílios que esquecemos da possibilidade de afeto e de relação que pode se configurar através dela. As redes sociais podem, dependendo do uso que damos a elas, constituir-se tanto como espaços de troca onde a comunhão social, o afeto e a valorização das relações são claramente percebidos quanto como espaços de distração e manipulação, fazendo com que esqueçamos da importância da sociabilidade para além do virtual. A internet, as redes sociais e as inovações decorrentes de tais tecnologias devem potencializar e melhorar nossos relacionamentos com as pessoas e com os lugares que nos rodeiam. E não apenas substituir por completo nossas vivências cotidianas estabelecidas no tempo presente e no espaço físico.

\section{Comprometimento social na contemporaneidade}

A relações estabelecidas através da internet nos levam a uma experienciação de mundo diferente da que tínhamos em outras épocas. As características contemporâneas podem nos guiar por caminhos focados 
apenas na convivência e despreocupados com o comprometimento social, o que gera uma constante passividade. Tal passividade repousa não só no fato de sermos sedentários e avessos a exercícios físicos e passeios ao ar livre; também se apresenta através da nossa falta de ação diante de causas sociais. A forma com a qual nos relacionamos com o mundo e com as pessoas bem como a maneira como nos comportamos tanto no ambiente virtual como no espaço físico são reflexos do interesse ou da falta de interesse nas questões que vão para além do nosso ego (ou ainda, para além do interesse do grupo de pessoas com as quais mantemos uma relação de maior intimidade). Talvez nos falte interesse no outro. É aqui que novamente percebemos o quanto somos, não raro, individualistas. E o quanto a coletividade, não raramente, mostra-se apenas na convivência superficial e rápida facilitada pela internet e pelas novas configurações de relacionamentos.

Todavia, isso tem mudado. Até pouco tempo, o comprometimento social era quase invisível nas redes, agora, ao navegar por plataformas sociais já podemos presenciar debates sociais, em forma de texto ou imagem. Logo, é fato, também, que as redes sociais realmente funcionam como espaço de convivência, de troca de informações e como ferramenta de encontro; afinal,

\footnotetext{
$<<$ há nesse desenvolvimento tecnológico outra maneira de viver o laço social ou, como acho mais adequado dizer, o 'laço societal'. Isto é, chegamos a uma sociedade que enfatiza a relação com o outro. E isso nos obriga a mudar nossa maneira de analisar a sociedade (MAFFESOLI, 2012, sem página).
}

Mesmo diante desse cenário, acredito que nem sempre unimos tal predisposição contemporânea ao laço social afetivo à preocupação real com o outro ou com a sociedade. Segundo Maffesoli (2012), a grande mudança vivida hoje é a passagem do indivíduo para a comunidade que, para Heidegger (1997), seria a transformação da sociedade do Eu para sociedade do Nós. Sim, somos/estamos ainda passivos e pouco engajados socialmente. Talvez estejamos começando uma tentativa de traçar um caminho que consolide essa passagem do eu para o nós atra- 
vés da união entre as novas maneiras de comunicação/relacionamento (que na pós-modernidade favorecem muito o estar-junto), a preocupação com o outro e, principalmente, a ação efetiva cujo intuito é construir uma sociedade mais afetiva. Afinal,

\section{$<<$ Existe hoje, em particular entre as jovens gerações, uma inegável vita- lidade, que se exprime em novas formas de solidariedade e de genero- sidade. A web favorece antigas formas de hospitalidade, que foram a marca das sociedades pré-modernas (MAFFESOLI, 2012).}

Percebemos que talvez nos falte mesmo união entre afeto e comprometimento social. $O$ afeto é muitas vezes esquecido diante de tantos incentivos consumistas que proporcionam uma suposta, e falsa, felicidade; é constantemente ocultado por trás dos elementos visuais em excesso e da valorização do eu (desvantagem do hedonismo contemporâneo). Sair do estado de parcial inércia próprio do que vivemos hoje é fundamental. Entrar em movimento e acompanhar a constante evolução tecnológica que aprimora as formas virtuais ou não de se comunicar e trocar informações é uma necessidade pós-moderna.

$\mathrm{O}$ afeto se mostra aliado às experiências sensíveis da contemporaneidade que tendem a ser cada vez mais interativas. Com as novas formas pós-modernas de se comunicar temos a possibilidade de estar mais horas por dia conectados às pessoas e aos acontecimentos que despertam nossos sentidos. Tal modo de se comunicar, quando visto e pensado enquanto experiência relevante e construtora de um conhecimento para além do tradicional, ajuda a promover um tipo de educação ligada às vivências, ao cotidiano. Podemos observar que o afeto, a vontade de estar com o outro e de fazer com que algo frutifique dessa relação é uma maneira, também, de despertar para a movimentação social tanto nas nossas atitudes mais corriqueiras no espaço físico como nas nossas ações dentro do ambiente virtual. A união entre afeto e movimentação social já se faz presente nas redes da internet. Não raro observamos páginas e comunidades que propagam informações textuais e visuais com temas relevantes para a construção de uma sociedade mais afetiva e 
mais preocupada com todos os seus integrantes. Tais informações propagadas na rede tornam a internet, além de um espaço de convivência no qual o estar-junto é o mote principal, uma ferramenta de manifestações fundamentalmente coletivas.

Estar comprometido socialmente, tanto no espaço físico quanto no virtual, é estar constantemente em movimento. Estar em movimento é estar motivado, de forma corpórea e intelectual, pelas paixões que nos mantém vivos. Acredito na paixão que move o mundo, que faz com que a existência caminhe de forma mais suave, tranquila e por vezes de forma firme e decidida.

Estar em consonância com o ritmo da movimentação social, ou seja, não estar passivo e estagnado ao que se apresenta diante de nós, é estar em constante transformação por alguma aspiração em comum. Existe coletividade neste processo, e existe, também, o desejo de reconfigurar o mundo com o olhar voltado ao outro. Trata-se de uma reestruturação. Por mim, pelos meus próximos e pela sociedade como um todo. Isso significa pensar em transformações guiadas a partir do afeto; é possível perceber amor nessa ação, e o amor tem pouco de racional. A modernidade, iniciada em meados do século XX, e a pós-modernidade ou modernidade líquida segundo Bauman (2001), sustentam grande parte de suas aspirações no racional, no explicável e na universalidade. Muitas vezes, não sobra espaço para a imaginação e para as possibilidades. Não raro, deixamos de perceber as peculiaridades de cada situação ou, até mesmo, a importância da coletividade no contexto social. Novamente nos deparamos com o tal individualismo dito ultrapassado. Individualismo este que, lembrando, caracteriza nossas relações sociais tão coletivas de um lado (comunicação rápida e facilitada pela internet, agrupamentos de pessoas para assistir futebol, etc) e tão solitárias, de outro. Talvez a mudança de paradigma só aconteça quando, de fato, apreendermos que somos uma "coletividade individualista".

$<<$ Quem sabe se, caso os poderes individuais, tão frágeis e impotentes isoladamente, fossem condensados em posições e ações coletivas, poderíamos realizar em conjunto o que ninguém poderia realizar sozinho? Quem sabe... O problema é, porém, que essa convergência e condensa- 
ção das queixas individuais em interesses compartilhados, e depois em ação conjunta, é uma tarefa assustadora, dado que as aflições mais comuns dos "indivíduos por fatalidade" nos dias de hoje são não-aditivas, não podem ser "somadas" numa "causa comum" (BAUMAN, 2001, p. 44).

Para Bauman, não existem mais lutas essencialmente coletivas; a pluralidade é tanta que os interesses em comum quase desaparecem. No entanto, relativizo tal opinião. Obviamente o que se realiza sozinho não tem a mesma força do que se realiza em conjunto; mas, nem sempre, a escolha das motivações em comum é um processo de responsabilidade exclusivamente nossa. Existem influências externas - como o Estado, o sistema econômico ou a mídia - que, muitas vezes, nos induzem a acreditar em certas verdades (não raramente, verdades absolutas e unificadas como o que acontecia no século passado) e a agir de determinadas maneiras. Por vezes, parece-me cada vez mais difícil - devido, talvez, ao acesso (excesso) de informações constantemente vazias ou sobre as quais são atribuídos valores irreais - entendermos nosso processo de construção de conhecimento e avaliar se ele, realmente, acontece de forma adequada e esperada. 0 excesso pode confundir e, em um mundo onde a "guerra" parece cada vez mais uma "promoção do livre comércio por outros meios" (BAUMAN, 2001, p.19), tornamo-nos gradativamente reféns dessas motivações reais e manipuladoras. $E$ quase imperceptíveis.

Influências externas podem dificultar o processo de construção de conhecimento o que pode determinar nossas próprias escolhas. Mas, em contrapartida (e assumindo novamente as minhas dúvidas em relação aos paradoxos vividos), Maffesoli (2005) nos sugere que todas as manifestações contemporâneas podem ser relevantes e importantes. Assistir uma ópera ou acompanhar uma novela, para o autor, são ações de extrema acuidade, pois assim como muitas outras, representam a contemporaneidade e ajudam a construir a percepção de mundo que hoje temos. Além disso, são essenciais para a construção de nossas personalidades. Se tais ações, banais ou não, representam-nos enquanto seres e enquanto sociedade é porque devem ser levadas em consideração como fonte de conhecimento e de experiências. 
É muito importante lembrar que, mesmo que para Bauman nossas atitudes cotidianas sejam cada vez menos motivadas socialmente e pareçam irrelevantes, e que para Maffesoli todas as vivências se estabeleçam de forma a prover resultados frequentemente positivos, a falta de atenção ao nosso cotidiano é um aspecto que pode determinar a qualidade de nossa vivência sensível. Além disso, fatores como a falta de atenção às experiências, políticas ou não, resultantes das nossas vivências diárias, além do descaso, ainda, com a educação para além das disciplinas tradicionais (com ementas e conteúdos programados que, muitas vezes, não permitem o vínculo entre conhecimento, a vida cotidiana e social), são fatores que podem interferir negativamente na forma como experienciamos o mundo à nossa volta.

\section{Ativismo Virtual}

Experienciar o mundo de modo a tentar vivenciá-lo coletivamente da melhor forma possível é experimentá-lo também a partir do afeto e das manifestações do nosso cotidiano. Tais manifestações se mostram muito produtivas quando apreendidas de maneira a levar em consideração e, principalmente, em relação, tanto experiências cotidianas frívolas quanto experiências voltadas ao comprometimento social. 0 equilíbrio e a reflexão sobre ambos os tipos de experiências são antecedidos, ou antecedem, os questionamentos próprios da filosofia e da vida dos sujeitos que mantêm laços com o outro, com o espaço em que vivem e, ainda, com os interesses sociais e afetivos que incitam a movimentação e a inquietação física e mental. Infelizmente, nem sempre alcançamos esta compreensão bipartida, complexa e produtiva.

O que está errado na sociedade em que vivemos, de acordo com Cornelius Castoriadis (1982, p.3), "é que ela parou de se questionar". Realmente, embora isso venha mudando, ainda nos questionamos pouco, e isso, apesar de parecer nos confortar, também nos acomoda. Talvez no falte uma base educacional sólida pautada na educação do sentidos. Para Duarte Jr. (1981), pode-ser dizer que a educação coloca (ou deveria colocar) as pessoas em contato com os sentidos que circulam em sua cultura, para que, assim, possam assimilá-los e nela viverem. Tal processo não significa que os sujeitos estarão assimilando o mundo de maneira 
passiva. Pelo contrário, para que se obtenha uma boa aprendizagem é necessário que as atitudes tomadas por tais sujeitos sejam conscientes isto é, sejam participativas e transformadoras da realidade interna e externa de cada um. Logo, segundo Paulo Freire (1996), o conhecimento necessita da curiosidade dos sujeitos e exige, da mesma maneira, a ação transformadora sobre a realidade, assim o processo de aprendizagem acaba por caracterizar-se por reinventar o que se aprende.

Entender as características do nosso tempo, suas particularidades, principalmente tecnológicas e de comunicação, é, também, reinventar o que aprendemos. Usar nossos conhecimentos em outros ambientes; experienciar as possibilidades e, enfim, experimentar construir, a partir dessas particularidades contemporâneas, a transformação interna e externa de nossas realidades, são ações que desenvolvem nossos conhecimentos e nos fazem aplicá-los ao cotidiano vivido. É importante permitir-se inserir na cultura vivida para aprender com ela e educar o sensível para assim entrar em um processo que permite a movimentação social. A configuração da pós-modernidade, com suas novas tecnologias de comunicação, principalmente a internet, potencializa as manifestações estéticas e permite, por vezes, um conhecimento da nossa atual cultura e dos hábitos próprios da nossa sociedade. Isso pode ser percebido nas redes.

No século XXI, principalmente devido à popularização da internet, novos meios de comunicação surgem e permitem que nossas experiências sejam potencializadas e levadas para além do espaço físico e do tempo conhecidos. Passamos a viver a cultura virtual dentro da própria cibercultura (cultura que surge a partir do uso dos computadores como meio de comunicação).

\footnotetext{
$<<$ O termo [ciberespaço] especifica não apenas a infraestrutura material da comunicação digital, mas também o universo oceânico de informação que ela abriga, assim como os seres humanos que navegam e alimentam esse universo. Quanto ao neologismo 'cibercultura', especifica aqui o conjunto de técnicas (materiais e intelectuais), de práticas, de atitudes, de modos de pensamento e de valores que se desenvolvem juntamente com o crescimento do ciberespaço (LÉVY, 1999, p. 17).
} 
A internet e os ambientes virtuais passam a se configurar como espaços de troca e como promotores de comunhão social pelo viés da coletividade. Os ambientes virtuais, ainda, se mostram importantes aliados dos movimentos sociais - também, propulsores de experiências estéticas - já que desmentem (ou desmitificam) muitas das informações manipuladas da mídia tradicional, permitem um diálogo mais democrático e fortalecem alguns laços sociais.

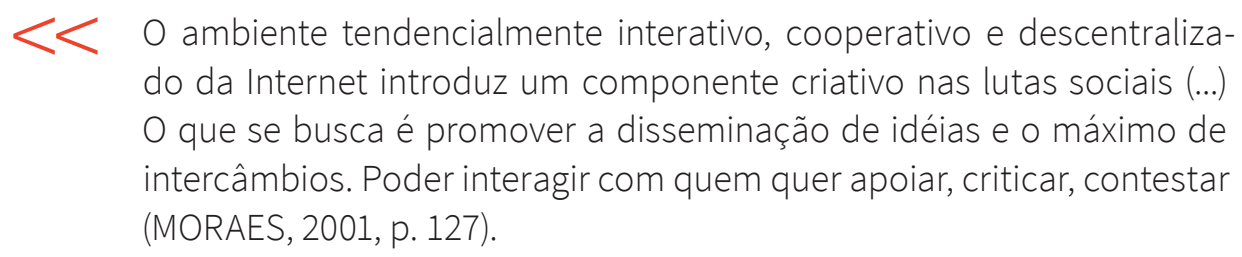

É essencial reforçar que com a internet são proporcionadas diversas possibilidades de relações sociais, de coletividades em torno de diferentes paixões em comum e de movimentações comprometidas socialmente. Mas ainda faltam peças que finalizem esse grande quebra-cabeça denominado contemporaneidade. Independentemente do ponto de vista, otimista ou não, podemos perceber e interpretar a contemporaneidade como uma época repleta de possíveis experiências nem sempre exploradas ao máximo. Uma hipótese talvez seja porque a carência de um saber sensível e, ao mesmo tempo, uma despreocupação com alguns movimentos socialmente comprometidos, mostrem-se constantes. A internet desvirtua, sim, muitos movimentos/conteúdos sociais ou mesmo desvaloriza diversos deles por meio de compartilhamentos de humor duvidoso e de dados irreais. Todavia, ainda assim, não faz inexistir os agrupamentos virtuais de cunho político e social, ou até mesmo, agrupamentos em torno de paixões cotidianas banais, tão importantes quanto os primeiros. Web e redes de comunicação virtuais se fazem importantes aliados nos processos de movimentação social crítica e, por isso, de conhecimento sensível.

A internet facilita a intercomunicação entre pessoas e agrupamentos que compartilham visões de mundo, sentimentos e desejos. Além disso, desbanca a hierarquização do poder comunicacional, tirando-o, muitas 
vezes, das mãos das mídias tradicionais onde o processo de comunicação é vertical, e o entregando aos sistemas horizontais de diálogo que favorecem o pluralismo político-cultural (MORAES, 2001). As redes funcionam como espaços virtuais de encontro que permitem, não raro, uma espécie de territorialização na medida em que extrapolam a comunicação virtual e se tornam ações no espaço físico. Além disso, transpõem o ambiente virtual, também, no momento em que a comunhão, o afeto e o anseio pela coletividade deixam de ser desejos para se tornarem aspirações reais, mesmo que por meio da internet. É a desejo de conviver com o outro aliado ao desejo de se viver em um mundo mais sensível.

Nessa esfera encontramos o "ativismo" e o "infoativismo" virtuais, ambos extremamente importantes como propulsores de ações e pensamentos críticos necessários à construção de um mundo mais democrático e compreensivo, e, consequentemente, ferramentas fundamentais na busca de espaços de convivência repletos de afeto. Ativismo é a busca a transformação da sociedade por meio da ação. $O$ ativismo está sempre ligado a um conjunto de princípios, em âmbitos diversos (SPRENGER, 2008), que geram uma movimentação que pode ser direta (de caráter físico, como manifestações de rua) ou indireta (através de meios que apresentam informações sobre as bandeiras levantadas, como o infoativismo). Ativismo é a aplicação destes princípios em qualquer atividade que tem, geralmente, caráter revolucionário, contrariando sistemas consolidados e instaurados. Mas ainda, e para além disso, ativismo é uma demonstração de paixão e uma tentativa de tornar o lugar no qual vivemos melhor ou mais sensível. Ou seja, quando nos propomos a lutar por alguma causa, estamos movidos por sentimentos de coletividade e de amor que nos fazem entender que uma nova configuração social permitiria que seres sociais de um determinado grupo ou tribo vivessem de forma mais harmoniosa. Logo, a movimentação ativa da sociedade pressupõe as aspirações das experiências estéticas cotidianas e do saber sensível: o desejo de fazer parte das coletividades, a vontade de me enxergar no outro e reconhecê-lo como legítimo outro e, consequentemente, o anseio de estruturar nossas relações através do afeto.

Nestes aspectos se concentra a importância social do ativismo. A vontade de construir com o outro e para o outro lugares e condições 
melhores de se viver, conduz nossas ações ativas através do âmbito da coletividade e faz com que nos deparemos novamente com a educação estética tão relevante para os tempos vividos. Fazer ativismo é, além de uma demonstração de afeto e de responsabilidade social, ensinar através da experiência. Quando levantamos determinada bandeira de luta em um protesto de rua ou compartilhamos uma imagem de conteúdo social estamos mostrando de forma estética, ou seja, através dos sentidos ou das sensações despertadas no outro a partir de nossa ação, que existem outras possíveis maneiras de pensar determinado assunto. Além disso, junto às pessoas que partilham da mesma causa ou ação ativista e àquelas pessoas por ela afetada, estamos colaborando para a constante construção de nossos conhecimentos individuais a partir do viés coletivo. Assim, fazer ativismo é não só colaborar para a construção de conhecimento em conjunto como ajudar na estruturação do nosso próprio eu. É a união entre alteridade, educação estética e afeto.

Assim, falar em ativismo é automaticamente falar em movimentação ativa da sociedade. Se para Bauman estes movimentos - de cunho político, preocupados com as causas sociais no viés do público - estão escassos, as agitações virtuais vêm mostrar que isto pode estar começando a se configurar de forma diferente. É possível perceber como o ativismo se faz presente nas redes sociais e como é facilitado, potencializado e, até mesmo, enriquecido através das discussões em tempo real e das informações descentralizadas próprias da internet. Refiro-me ao ciberativismo, forma de ativismo realizado através de meios eletrônicos como a internet, usados para fazer reinvidicações e organizar mobilizações. 0 ciberativismo acaba funcionando como uma alternativa aos meios de comunicação de massa tradicionais, permitindo a participação de novas formas de pensar, além das propagadas no monopólio da opinião pública.

$<$ É possível ser dito que a Internet se constitui uma ferramenta imprescindível para as lutas sociais contemporâneas, já que facilita as atividades (em termos de tempo e custo), pode unir e mobilizar pessoas e entidades de diferentes localidades em prol de uma causa local ou transnacional, bem como quebrar o monopólio da emissão e divulgar informações "alternativas" sobre qualquer assunto (RIGITANO, 2003, p. 2). 
Podemos perceber e pensar o ativismo como ferramenta para propor uma nova maneira de se relacionar com os espaços que nos rodeiam e com as pessoas com as quais convivemos. É claro que existem diversas outras formas, já inventadas ou não, de fazermos nossa parte por um mundo mais sensível e de mobilizarmos a sociedade a buscar isso conosco. Todavia, as lutas em comum, permeadas por afeto, amor e reconhecimento do outro, são manifestações que se fazem em coletividade e que propiciam trocas de experiências individuais, construção de experiências em coletividade e, principalmente, proporcionam relações de afeto que através da internet podem se multiplicar e se fortalecer.

\section{Considerações Finais}

Diante de toda essa discussão, é possível concluir que com suas novas maneiras de ver e vivenciar o mundo a internet apresenta-nos diversas possibilidades de relacionamento colaborando para que estejamos cada vez mais conectados tanto do ponto de vista técnico, quanto do afetivo. Estando mais próximos do outro, de seu cotidiano e suas paixões, podemos ter as trocas sociais multiplicadas. Tais trocas colaboram na elaboração de nosso entendimento de mundo e, principalmente, na construção de nossas diversas singularidades, processo essencial na inserção em uma sociedade virtualizada e eclética. Conquanto, a aproximação nem sempre acontece, e muitas vezes a falta de contato físico acaba por fragilizar os laços sociais. Isso acontece, também, por resistirmos ao fato de a internet funcionar como ambiente de aprendizagem bem como por ainda não considerarmos o banal e cotidiano, pelo viés da estética, enquanto efetivos educadores. Desta maneira, muitas vezes não permitimos nos enxergar no outro e passamos a ignorar quaisquer ações que sejam beneficiadoras deste mesmo. Embora a sociedade virtual se mostra gradativamente mais preocupada socialmente, esse movimento é recente e ainda se mostra tímido. Por isso, na sociedade pós-moderna é essencial estar aberto a uma agenda política e social e, antes de tudo, estar aberto a relacionamentos plenos com o outro, no qual ambas as partes trabalham juntas na busca de lugares e situações melhores de se viver. O comprometimento social, então, está diretamente ligado ao ativismo, ou seja, ao desejo de estabelecer um 
laço com o outro e fazer com que algo frutifique desta relação. Assim, o ativismo pressupõe um agir coletivamente em consonância com o outro numa relação de amor e respeito e acaba, igualmente, e através deste afeto, por funcionar como manifestação que contesta sistemas e ideologias já instaurados. Com a internet essas manifestações sociais têm se tornado mais frequentes e têm, da mesma maneira, alcançado e conquistado um número maior de pessoas. São as redes sociais potencializando as maneiras de se relacionar com as pessoas e com a sociedade em sua totalidade. Nesse contexto encontramos diversas formas de fazer ativismo: textos em blogs, petições online, vídeos e imagens com conteúdos sociais, etc. Através da internet esses modelos estéticos se propagam de forma exponencial e se mostram tão importantes quanto às manifestações de rua, por serem, justamente, elementos com os quais nos identificamos e que são constantemente visualizados em nosso cotidiano.

\section{Referências}

BAUMAN, Zygmunt. Globalização: as conseqüências

humanas. Rio de Janeiro: Jorge Zahar, 1999.

Identidade. Rio de Janeiro: Jorge Zahar, 2005.

Modernidade líquida. Rio de Janeiro: Jorge Zahar, 2001.

O Mal-Estar da Pós-Modernidade.

Rio de Janeiro: Jorge Zahar, 1998.

CASTORIADIS, Cornelius. A Instituição imaginária

da sociedade. Rio de Janeiro: Paz e Terra, 1982.

(Coleção Rumos da cultura moderna; v.52)

DUARTE JR., João Francisco. 0 Sentido dos sentidos: a

educação (do) sensível. Campinas, 2000. Tese.

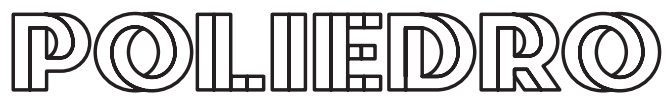


FREIRE, Paulo. Pedagogia da autonomia. 27a

Ed., São Paulo: Paz e Terra, 2003.

HEIDEGGER, Martin. A questão da técnica. Cadernos

de Tradução. São Paulo: USP, 1997.

LÉVY, Pierre. Cibercultura. São Paulo: Editora 34, 1999.

0 que é o virtual?. São Paulo: Editora 34, 1996.

MAFFESOLI, Michel. A contemplação do mundo.

Porto Alegre: Artes e Ofícios, 1995.

A espiral de Maffesoli [2012]. São Paulo:

Jornal Valor. Entrevista concedida a José Castello. Disponível em: <http://www.ihu.unisinos.br/noticias/514073-a-espiralde-maffesoli>. Acessado em: 20 de setembro de 2015.

\section{A Transfiguração do Político: a tribalização}

do mundo. Porto Alegre: Editora Sulina, 1997.

. O mistério da conjunção: ensaios sobre comunicação, corpo e socialidade. Porto Alegre: Editora Sulina, 2005.

O tempo das tribos: o declínio do individualismo nas

sociedades de massa. Rio de Janeiro: Forense Universitária, 1998.

Sociólogo Michel Maffesoli fala da retomada

de manifestações juvenis: depoimento. [9 de abril de 2013]. Porto Alegre: Zero Hora. Entrevista concedida a Gabriel Brust.

MORAES, Dênis de. 0 concreto e o virtual: mídia, cultura e tecnologia. Rio de Janeiro: DP\&A, 2001. 
RIGITANO, Maria Eugenia Cavalcanti. Redes e ciberativismo: notas para a análise do centro de mídia independente. Rio de Janeiro: Bocc, 2003. Disponível em http://www.bocc.ubi.pt/pag/rigitanoeugenia-redes-e-ciberativismo.pdf. Acessado em: 24 de agosto de 2015.

RECUERO, Raquel. Redes sociais na

internet. Porto Alegre: Sulina, 2009.

SPRENGER, Lourdes. Conceito de ativismo. Porto Alegre: 2008. Disponível em: < http://solidariedadeanimal.blogspot.com.br/2008/04/ conceito-de-ativismo.html>. Acessado em: 02 de junho de 2015. 